\title{
MULHERES CATÓLICAS REDESENHAM O CATOLICISMO: ENSAIO EM HOMENAGEM A MARIA JOSE ROSADO NUNES
}

\author{
Mary E. Hunt \\ Traduzido por: \\ Lula Ramires*
}

\section{RESUMO}

Este ensaio explora de que maneira as mulheres católicas têm transformado o catolicismo enquanto cultura, quiçá a própria igreja institucional, entre as décadas de 1970 e 2020. Nós, mulheres católicas, não nos fizemos amáveis à hierarquia católica; é bem verdade que muitos não gostam de nós e nos temem. Mas temos salvado vidas, tanto espirituais quanto físicas, fazendo uma forte oposição e proporcionando alternativas criativas à igreja institucional. Uma reformulação do catolicismo começa pela cultura e pelo ethos. As mulheres católicas preconizam isto na forma de um movimento global enraizado em culturas particulares, unidas pelos valores do amor e da justiça, abertas à sabedoria de muitas tradições religiosas e estruturadas para proporcionar ministério e sentido através de comunidades colaborativas organizadas horizontalmente. Se por um lado as coisas progrediram, de outro muito trabalho ainda precisa ser feito.

\section{INTRODUÇÃO}

Maria José Rosado Nunes é uma querida companheira, pela qual tenho profundo respeito, nas lutas pelo bem-estar das mulheres, particularmente na área dos direitos reprodutivos. Há décadas realiza

* Dra. Mary E. Hunt é uma teóloga feminista que é co-fundadora e co-diretora da Aliança de Mulheres pela Teologia, Ética e Ritual (WATER) em Silver Spring, Maryland, EUA. Sendo uma católica ativa no movimento de igreja para e pelas mulheres, leciona e escreve sobre teologia e ética, com atenção especial às questões de justiça social.

** Graduado e licenciado em Filosofia (FFLCH), Mestre e Doutorando em Educação (FE) pela Universidade de São Paulo. É membro do Grupo de Ação Pastoral da Diversidade, de São Paulo, SP. Tradutor técnico especializado em versão de textos acadêmicos para a língua inglesa. Contato: lularamires@usp.br 
um trabalho criativo, destemido e pioneiro que é um legado para brasileiras e brasileiros como também para outras pessoas que lutam por justiça no mundo inteiro. Como socióloga altamente qualificada, alguém que é profundamente versada em questões teológicas, filosóficas, artísticas e culturais, Zeca, como é conhecida por todas e todos, é uma colaboradora única e valiosa.

Nós nos conhecemos décadas atrás através de Católicas pelo Direito de Decidir, como era chamado desde aquela época, e também em círculos teológicos feministas internacionais. Tenho o privilégio de colaborar com ela e sua maravilhosa equipe em Católicas ao longo de anos. Fazem um trabalho fabuloso! Aprecio imensamente sua amizade e hospitalidade. E meu desejo é que por muitos anos ainda estaremos juntas num mundo que dolorosamente necessita dessas fortes relações entre mulheres que se veem como irmãs. Sou apenas uma dentre muitas de suas amigas que se levantam para agradecer e aplaudi-la neste aniversário especial.

\section{CATOLICISMO}

O meu foco crítico é no catolicismo porque ele é o fundamento da história de vida da Zeca. Tendo feito seus estudos em ambiente católico, pertenceu durante anos a uma ordem religiosa católica e depois uniu sua vida à de um ex-padre jesuíta, dois importantes aspectos de sua trajetória. Porém, mais revelador, no caso da Zeca, assim como muitas católicas e católicos, os valores - profundamente imbuídos - do amor e da justiça que se dão em sacramento e solidariedade são as áreas do catolicismo que ela levou a sério. Não me refiro em primeiro lugar aos sacramentos da igreja. Ao contrário, ela desenvolveu e vive um apreço aos sagrados aspectos de todas as formas de vida. Em seu trabalho, tem se dedicado a aprimorar as opções para aquelas e aqueles que têm muito pouco, compartilhando recursos com a comunidade mais ampla e depositando seus esforços intelectuais e organizacionais para criar espaço para que mais pessoas possam melhorar de vida. Essa abordagem, e não a da igreja institucional, descreve uma abordagem "católica” na pós-modernidade.

Alguns podem considerar um desperdício de esforços se importar com a Igreja Católica Romana, cuja poeira muitas e muitos de nós 
lançamos fora de nossas sandálias. Mas seria irresponsabilidade ignorar o catolicismo que, como todas as tradições religiosas, tem poder para o bem, mas especialmente, por causa da perniciosa propensão patriarcal da instituição católica de fazer um grande mal. Seria deixar de analisar um dos motivos principais do porque as mulheres, especialmente as mulheres pobres e marginalizadas, não terem acesso a um efetivo e econômico controle de natalidade ou ao aborto. É por essa razão que mulheres lésbicas, bissexuais, trans e outras pessoas não-heterossexuais são discriminadas pelas leis cujas raízes e justificativas residem nos ensinamentos (i)morais do catolicismo institucional.

Ignorar esta instituição, ainda que em grande medida ela esteja em declínio, seria ingênuo se levarmos a sério a necessidade de transformação social. A instituição ainda desempenha um papel na sociedade, frequentemente ao batizar e crismar, conferindo sagrada legitimidade à opressão das mulheres. Isto é inaceitável. Algumas de nós, que conhecemos bem a igreja, assumimos nossa responsabilidade de erradicar tal injustiça. Por isso, empreendemos a iniciativa de redesenhar a tradição.

Neste ensaio, me atenho ao modo como as mulheres católicas tem modificado o catolicismo como uma cultura, se não tanto na igreja institucional, nos anos em que Zeca e eu estivemos envolvidas, sobretudo entre 1970 e 2020. Neste período de 50 anos que se seguiu ao Concílio Vaticano II, as mulheres católicas, entre elas Zeca e suas companheiras na academia ou na luta por mudanças sociais, desempenharam um papel fundamental. Não nos fizemos amáveis às hierarquias católicas; de fato, muitos não gostam de nós e nos temem. Mas, imagino que tenhamos salvado vidas ao fazer uma forte oposição e oferecer alternativas criativas à igreja institucional.

A consequência disso foi uma reformulação do catolicismo começando pela cultura e pelo ethos. Projetamos essa mudança na forma de um movimento global enraizado em culturas particulares, unidas por um compromisso aos valores do amor e da justiça, abertas à sabedoria de muitas tradições religiosas e estruturadas para oferecer ministério e significado através de comunidades horizontalmente organizadas em espírito cooperativo. Ainda que tenhamos tido progressos, estamos bem longe do alvo. 
O problema não é simplesmente que a Igreja Católica Romana se oponha em reconhecer a plena humanidade e bem-estar das mulheres. É que este mesmo aparato defende crimes indefensáveis como o abuso sexual pelo clero e o acobertamento pelo episcopado. A mesma instituição busca manipular o consenso global em questões vitais e continua mantendo um modo monárquico de governar. Apesar de algumas intervenções sociais úteis, tal qual a encíclica Laudato Si' do Papa Francisco sobre o meio ambiente, há sempre um asterisco: isto teria ficado bem melhor se tivesse incorporado a experiência das mulheres. No caso da Laudato Si', o esforço é prejudicado pelo fato de que a proibição do controle da natalidade, componente chave na luta global por justiça em relação às mudanças climáticas, é mantida intocada, enfraquecendo, deste modo, a força de um documento comprometendo sua utilidade.

Em grande medida, a Igreja Católica Romana institucional, e alguns acrescentariam a cultura católica, não mudou nada nos últimos 50 anos. A mulheres não são ordenadas. Em algumas dioceses, as meninas não podem nem ser coroinhas. Os ensinamentos da teologia moral sobre o controle de natalidade, o aborto e o amor entre pessoas do mesmo sexo permanecem mergulhados em desinformação e discriminação. Poucas mulheres têm qualquer jurisdição em assuntos de governança eclesial, embora haja atualmente mulheres em posições de liderança (Celia WEXLER, 2020). Mas as exceções comprovam a regra, isto é, que uma metade inteira dos bilhões de católicos no mundo ainda não têm voz nos processos de tomada de decisão da igreja institucional.

Contudo, o poder católico não perdurou por dois milênios por obra do acaso. A capacidade da instituição de cooptar os que resistem ao seu modo de ser é lendária. Por exemplo, naquilo que foi recentemente anunciado como um avanço, uma mulher foi nomeada Subsecretária de Estado (VATICAN NEWS, 2020). Seu portfólio inclui as Nações Unidas, onde o Vaticano notoriamente arregimenta países conservadores para formar coalizões que são um entrave ao consenso no tocante a assuntos de saúde reprodutiva das mulheres.

A nomeação de uma mulher para este cargo espelha ações dos 25 anos anteriores em que o Vaticano enviou sua delegação, chefiada por uma mulher, à $4{ }^{\text {a }}$ Conferência sobre as Mulheres das Nações Unidas em 
Pequim em 1995 (Ian JOHNSON, 1995). Os resultados foram desastrosos para as mulheres do mundo inteiro. Este movimento demonstrou como o Vaticano pode ser hábil em manter seu poder, mesmo a ponto de deixar que uma mulher liderasse uma delegação que, naquele momento, teria sido liderada por um membro do clero. Há mulheres, como Mary Ann Glendon, que lideraram delegações, dispostas e bastante capazes de fazê-lo, embora suas visões sejam antifeministas. O resultado é uma mudança cosmética quanto ao gênero, mas a continuidade da mesma ideologia antifeminista. O Vaticano é esperto, e nada o detém quando se trata de arregimentar mulheres que o apoiem.

Apesar destas deprimentes realidades, considero que o impacto de Zeca e de outras católicas feministas é profundo e duradouro. A Igreja Católica Romana nunca será a mesma agora que as mulheres no mundo inteiro estão cientes de sua ideologia e deslealdade.

Explorarei três áreas em que este fato é evidente: na pertennça, na teologia moral e no ministério.

\section{PERTECIMENTO}

É difícil medir a pertença religiosa. Os registros de batismo e participação dos fiéis nas paróquias são tradicionalmente citados para mostrar quantos católicos há no mundo. Os números estão ao redor de 1,3 bilhão ou aproximadamente $17 \%$ da população mundial (SALA DE IMPRENSA DA SANTA SÉ, 2019). Mas os números também indicam que enquanto o catolicismo está crescendo na Ásia e na África, este não é caso na Europa ou nos Estados Unidos que são nações que fazem grandes doações. Curiosamente, a América Latina é adicionada à América do Norte nas estatísticas do Vaticano, com a dura admissão de que o percentual católico da população nos países do sul é muitas vezes maior do que os países do norte em toda as Américas. O Vaticano admite que há um rápido encolhimento no número de sacerdotes masculinos.

As estatísticas de batismo são enganosas. Se por um lado representam sem dúvida um retrato instantâneo de algo que aconteceu, embora muitos anos atrás para algumas pessoas, estes números não refletem a realidade de que muita gente está abandonando a igreja, algo prevalente hoje em dia especialmente nos países do norte e do ocidente. 
Assim, ainda que as estatísticas batismais possam revelar uma tendência, observações in loco contam outra história. Por exemplo, nos EUA, a maior denominação religiosa única é a católica (David MASCl; Geogory A. SMITH, 2018). Mas o "Estudo do Panorama Religioso, de 2014, do Pew Research Center... constatou que a proporção de americanos que são católicos caiu de 24\% in 2007 para 21\% em 2014" (David MASCl; Geogory A. SMITH, 2018, s/n). Não se trata de algo trivial, especialmente num país que faz uma contribuição substancial aos cofres do Vaticano. Do mesmo modo, no Brasil, o número de católicos caiu em milhões (Kenneth RAPOZA, 2016). É claro que há muitas razões para isto, entre elas o crescimento de alguns grupos evangélicos e pentecostais. Mas o êxodo relacionado a fatores envolvendo as mulheres desempenha um grande papel neste declínio.

Por que as pessoas abandonam a Igreja Católica Romana? Primeiro, tanto as mulheres quanto os homens essão desanimados e desencantados com a liderança e com o ministério oficial da igreja que são exclusivamente masculinos. Esta questão tem sido frequente por mais de 50 anos, por isso não há muito a ser dito aqui. Ou as mulheres, os LGBTIQ e as pessoas casadas são ordenadas, ou as estruturas eclesiais mudam para que a hierarquia clero/leigos seja nivelada. Não há outra alternativa - inclusão total ou mudança estrutural. A rápida proliferação das igrejas domésticas e das pequenas comunidades de base que são independentes de qualquer estrutura católica, demonstra que "católico" agora assume muitas formas, sendo a expressão institucional apenas uma delas. As pessoas não vão esperar por Roma. Trata-se de um deslocamento cultural.

A questão problemática é que somente os clérigos ordenados têm jurisdição ou poder de decisão, e leigas e leigos não. Por isso, para se criar formas igualitárias de comunidade, muito mais pessoas precisam ser ordenadas ou o sistema inteiro precisará ser substituído. Não vejo nenhum destes cenários acontecendo a curto prazo, como também não o veem milhões de outras pessoas que abandonaram a igreja. As mulheres católicas, como será evidenciado abaixo, simplesmente seguem em frente e se engajam no ministério. Muitas pessoas preferem comunidades lideradas por mulheres do que as conduzidas por homens, 
especialmente numa época de abuso sexual do clero e acobertamento desta realidade, e todas elas se consideram católicas. Esta é a mudança.

Em segundo lugar, muitas pessoas que estão indo embora, e mesmo aquelas que ficam, rejeitam os ensinamentos da instituição sobre controle de natalidade, aborto, divórcio e amor entre pessoas do mesmo sexo como nocivos a si mesmas e a seus filhos e filhas. O problema é duplo: os próprios ensinamentos não condizem com a experiência e o compromisso de católicos e católicas contemporâneos e, por outro lado, a duplicidade com a qual estas questões em particular são escolhidas e enfrentadas escandaliza muita gente.

Dizer às pessoas publicamente que é errado usar métodos contraceptivos e, nas conversas privadas, os padres dizerem que devem usar seu próprio discernimento é uma abordagem que era comum quando a encíclica sobre controle de natalidade Humanae Vitae surgiu em 1968. Os padres temem por suas próprias carreiras eclesiais. Mas são as mulheres que assumem o fardo desproporcional nestes casos, especialmente se não utilizam métodos contraceptivos e precisam lidar com uma gravidez involuntária. Assim, embora o ensinamento está antiquado, o método de transmissão é simplesmente repugnante.

A mesma dinâmica ambígua se esgota agora quando padres gays, alguns deles sexualmente ativos, pregam contra o amor entre pessoas do mesmo sexo, classificando-o como pecaminoso. Os jovens pagam o preço por isso; muitos tentam o suicídio por causa das noções equivocadas que lhes são ensinadas de que sua orientação sexual é desordenada e sua atividade sexual é maléfica. Católicos e católicas reconhecem e cobram estas normas equivocadas. Mas muitos estão somente preocupados com os enganos que cada vez mais vêm a público.

Em terceiro lugar, as pessoas deixam o catolicismo porque dispõe de muitas outras boas opções religiosas. Pequenas comunidades de base ou igrejas domésticas, denominações protestantes liberais com foco nos sacramentos como as igrejas luterana e anglicana que incluem mulheres nos postos de liderança e ministérios e que envolvem a participação dos seus membros na tomada de decisões são bastante atrativas a católicos que buscam o mesmo. Tradições como o budismo, que ressoam com o catolicismo em termos de uma rica espiritualidade, estão entre as muitas 
alternativas no mercado espiritual. Católicos e católicas não precisam restringir a si mesmos a uma única tradição: alguém pode ser católico budista ou anglicano católico, por exemplo.

Estudiosas feministas da religião têm explorado muitos grupos maravilhosos de culto à Deusa, grupos Wiccan, pagãos e indígenas que fornecem inspiração para algumas pessoas pós-modernas. Eles/as têm encontrado profundos paralelos com coisas católicas, por exemplo, algumas igrejas marianas têm se apoiado em sítios de Deusas da antiguidade. Simplesmente, não há termo de comparação entre a espiritualidade saudável e útil que bebem nestas fontes e aquilo que o catolicismo institucional, que discrimina ativamente as mulheres, oferece.

Contingentes cada vez maiores de pessoas se identificam com 'nenhuma' no caso de 'nenhuma das anteriores' quando se trata de assinalar a preferência religiosa, optando muitas vezes por serem espiritualizadas, mas não religiosas. Todas estas opções são reais e estão disponíveis, são respeitáveis e gratificantes. É surpreendente que o catolicismo não tenha perdido mais pessoas em sua resistência à mudança.

Outro motivo pelo qual as pessoas estão deixando o catolicismo, especialmente em países europeus como a Alemanha e a Suíça onde são obrigados a pagar impostos à igreja, se dá pelo fato de que não quererem que seu dinheiro seja usado para oprimir as pessoas, particularmente as mulheres em idade reprodutiva. Eles/as têm a opção de fazer uma petição formal de sair da igreja. Muitos/as o fazem, a despeito do fato de que não possam mais ser empregados/as por uma entidade católica ou ser enterrados/as num cemitério católico. Não tenho conhecimento quanto aos escrúpulos adotados quando estas ações nos vários países são reportadas ao Vaticano. Mesmo que as informações sejam precisas, duvido que o Vaticano se preocupe em subtrair esses números das estatísticas globais quanto ao pertencimento.

Todas estas e outras razões refletem o impacto do trabalho crítico feminista na religião que fez profundas incursões na psique e no espírito de muitos católicos. Não se pode mais mentir ou enganar os/as católicos/ as. Mulheres teólogas, canonistas, biblistas e ministras contribuem mudanças fundamentais no pensamento e na prática. A igreja institucional continua a resistir a tais mudanças. Enquanto isso, seu número cada vez 
menor de adeptos pensa cada vez mais por si mesmo e, assim, define uma trajetória na direção que as católicas feministas estão modelando.

\section{TEOLOGIA MORAL}

A teologia moral é uma forma modeladora no catolicismo. Não é porque seja sempre útil, mas porque a Igreja Católica Romana é uma das poucas instituições da sociedade que propõe alegações éticas universais às quais as pessoas dentro e fora da igreja prestam alguma qualquer atenção. Algumas destas alegações, como a oposição à pena de morte e o incentivo a um futuro que leve em conta a ecologia, são úteis. Mas as reivindicações sobre saúde reprodutiva, especialmente a rejeição ao controle de natalidade e ao aborto, bem como os ensinamentos anti-LGBTIQ, são profundamente problemáticos. A falta de informações científicas embasadas e a escassez de diferentes vozes e visões no debate lançam os ensinamentos da instituição na lata de lixo da história.

Os ensinamentos são dúbios em si mesmos e perigosos no impacto que têm sobre as leis e regulamentações em muitos países. Não é exagero dizer que as mulheres perdem suas vidas por causa de ensinamentos católicos sobre controle de natalidade. Elas têm sido proibidas, por leis baseadas nos ensinamentos católicos em alguns países, de obter anticoncepcionais legalmente. Pelo mesmo motivo causado por noções católicas, algumas mulheres morrem ao fazerem abortos em condições de ausência de esterilização e procedimentos seguros. Elas simplesmente não têm acesso a opções legais, acessíveis e salubres, sobretudo, mulheres pobres e jovens que não dispõem dos meios para driblar as leis, quando estes meios estão disponíveis para muitas mulheres mais velhas e com maior poder aquisitivo.

Mulheres estudiosas e ativistas têm produzido alternativas saudáveis, inclusivas e éticas que atualmente são a base da justiça reprodutiva para as mulheres. Zeca e suas companheiras em CDD do Brasil estão na frente de batalha deste movimento que envolve questões tanto teológicas quanto jurídicas. São esforços de católicas e católicos que produzem novas maneiras de ser católico/a. E a mudança funciona deste jeito.

A oposição à Humane Vitae ainda ecoa. A teóloga católica feminista Rosemary Radford Ruether escreveu parte do seus primeiros trabalhos 
em teologia contemporânea sobre o controle de natalidade (Patricia MILLER, 2014). Era uma estudiosa dos clássicos e especialista da Igreja Primitiva por formação, mas as realidades de ser uma mulher católica em idade fértil para engravidar participando de uma igreja que provocava problemas existenciais foi o suficiente para dar o pontapé inicial em sua brilhante carreira como teóloga, especialista em ética e historiadora da igreja. Leu os primeiros textos da Patrística escritos pelos chamados Padres da Igreja (Orígenes, Tertuliano etc.), mas com lentes feministas, denunciando a misoginia desde os primórdios. Rosemary foi durante muito tempo uma das diretoras das Católicas pelo Direito de Decidir nos EUA, e uma assídua contribuidora da publicação desta entidade, Conscience. É uma convicta defensora das pessoas LGBTIQ+ que dedicou boa parte de seu trabalho através da pesquisa acadêmica e da militância para criar esta nova cultura católica.

Mary Daly, filósofa e teóloga feminista, veio da tradição católica. Ela também realizou trabalho de lançar as bases e fundamentar a morte do catolicismo romano patriarcal. Seu insight simples, porém brilhante, "Se Deus é masculino, então o masculino é Deus", foi o início do fim do privilégio masculino sancionado pela religião (Mary DALY, 1973).

É impossível superestimar o poder dos estudos feministas da religião na desconstrução do catolicismo romano. Pesquisa feministas em história, estudos bíblicos, práticas litúrgicas, linguagem inclusiva, relações com as religiões mundiais, acompanhamento e aconselhamento pastoral, ética, artes religiosas e tantas outras áreas de investigação alteraram o panorama intelectual. As mulheres estão aprendendo não apenas a pensar por si mesmas, mas também a rejeitar a imposição do conhecimento onde o masculino prevalece.

Muitas não se preocupam se sua produção intelectual e espiritual tem a aprovação da Igreja Católica Romana. Mas dadas as fontes e os antecedentes das pesquisadoras, tal trabalho pode legitimamente reivindicar-se "católico" por aquelas que desejam, sem que concedamos toda esta autoridade à instituição. Isto é parte da reforma ou reformulação que tenho em mente, que turva as linhas entre o catolicismo institucional e a emergente cultura católica. 
O aborto é uma questão ética central para católicas e católicos. É frequentemente a pedra de toque da ortodoxia para aqueles/as que podem discordar da exclusão das mulheres da ordenação, a proibição do controle de natalidade e muitas questões anti-LGBTIQ. Entretanto, alguns não conseguem sequer se posicionar a favor do direito das muIheres à justiça reprodutiva. Por isso, não surpreende que os primeiros trabalhos feministas sobre o aborto não foram desenvolvidos por estudiosas feministas católicas, apesar de sua erudição. Nem que muitas das melhores e mais brilhantes mulheres católicas tenham sido excluídas do ministério ordenado, tal como aconteceu inicialmente quando algumas denominações protestantes começaram a ordenar mulheres fazendo com que poucas seguissem carreira acadêmica.

Ao invés disso, veio da militante e pesquisadora presbiteriana Beverly Wildung Harrison. Ela era uma grande conhecedora da tradição de lei natural católica e tinha uma profunda ligação com os trabalhos de feministas católicas nas questões éticas, inclusive o de Margaret Farley'. Em seu livro notório, Our Right to Choose: Toward a New Ethic of Abortion, Beverly Harrison lançou os contornos de uma perspectiva cristã pró escolha (Beverly Wildung HARRISON, 1984). Ela elegeu a agência moral das mulheres e a integridade de seus corpos como fundamentos para esta posição. Com isso, ela queria dizer que a possibilidade de escolha por parte das mulheres é um bem moral, mesmo se cada uma das escoIhas feitas por uma mulher não seja boa. E a única relação que um feto tem com uma mulher grávida reside no fato, primeiro e primordial, de que o feto é parte do corpo da mulher. Assim, o bem-estar da mulher, e não simplesmente o bem-estar do feto, é parte da equação moral.

Esta análise mudou o discurso, inclusive entre as feministas católicas, passando da questão se o aborto era ou não um pecado, se os

\footnotetext{
Margaret Farley, uma Irmã da Misericórdia e Professora na Yale Divinity School, foi uma das signatárias da A Catholic Statement on Pluralism and Abortion (uma declaração católica sobre o pluralismo e o aborto), publicada no New York Times em 1984 reconhecendo uma variedade de visões católicas sobre o aborto, incluindo aquelas pró escolha. Posteriormente, ela foi punida pelo Vaticano por seu livro Just Love: A Framework for Christian Sexual Ethics. Nova York: Continuum, 2006. O foco da crítica deles era a aceitação do casamento entre pessoas do mesmo sexo como um bem moral e seu franco reconhecimento de que a masturbação não era moralmente maléfica.
} 
fetos constituem pessoas, se o feto ou a mulher tinha prioridade e outras questões equivocadamente colocadas para a preocupação básica com o bem-estar da mulher na complicada realidade da gravidez num mundo racista, sexista e economicamente injusto.

As posições católicas pró escolha tenderam a se desenvolver não tanto pelas teólogas ou especialistas em éticas individualmente, mas pelos grupos e organizações. Este é um papel central que grupos de Católicas pelo Direito de Decidir no mundo inteiro desempenharam no desenvolvimento do corpo cada vez maior de pesquisadoras, ativistas, operadoras do direito e ministras que assumiram a especial responsabilidade de desmantelar a forte oposição católica ao aborto baseada em visões de mundo misóginas. Atualmente, ser uma católica ou católico pró escolha não é mais uma contradição nos termos. É uma declaração do fato que revela tão somente as muitas maneiras que existem de ser católica ou católico para além da trajetória da igreja institucional. É claro que pessoas que sustentam estas visões são detratadas e rejeitadas pela hierarquia, como experienciado pela teóloga brasileira Ivone Gerbara, mas agora simplesmente não há como colocar a pasta de dente de volta no tubo. Católicas e católicos pró escolha são católicas e católicos.

Convém observar que a liderança de Ivone no eco-feminismo é reconhecida mundo afora. Felizmente, ela não limitou o alcance de sua reflexão à comunidade católica, mas entende, em termos feministas, que a destruição ambiental é uma violenta e perigosa ameaça que vai muito além da capacidade de qualquer grupo dar conta sozinho. É uma pena que o Papa Francisco não a tenha convidado para ser coautora do Laudato Si'. Teria sido um documento bem mais eficaz caso ela tivesse introduzido nele suas sensibilidades como 'católica' e feminista católica.

O amor entre pessoas do mesmo sexo é outro bom exemploda reformulação do catolicismo. Tal como acontece com o aborto, depois de muita pesquisa acadêmica, centenas de encontro, conferências, comunicados à imprensa e coisas do tipo, simplesmente não há mais maneira de negar a realidade das e dos/as católicos/as LGBTIQ, seus amigos e apoiadores. As teologias feministas foram a base que funda- 
mentaram muitas abordagens queer à religião, inclusive ao catolicismo². Enquanto a igreja institucional lamenta e range seus dentes coletivos, a não aceitação de sua posição é evidente por muitos/as que se identificam como católicos/as queer. A duplicidade de muitos, sexualmente ativos, clérigos gays, tentando vender um produto moral defeituoso, é um padrão que conhecemos bem.

Estas questões éticas se alteraram e desenvolveram com o tempo de tal modo que as visões comumente sustentadas sobre controle de natalidade, aborto, amor entre pessoas do mesmo sexo e temas correlatos estão se tornando cada vez mais normativas entre católicas e católicos. Isto é verdade tanto para aqueles que continuam a participar da vida na igreja quanto para aqueles que não mais o fazem, o que significa que se trata, obviamente, de uma mudança na cultura católica. É uma transformação significativa.

\section{MINISTÉRIO}

Nenhuma questão é mais emblemática do patriarcado católico do que a não ordenação das mulheres (Elisabeth SCHÜSSLER-FIORENZA; Hermann HÁRING, 1999)3. As discussões ad nauseam nos últimos 50 anos resultaram mulheres ordenadas como diaconisas, sacerdotisas e bispas sem nenhum caráter lícito ou validade. Mesmo o recente clamor pelos povos da Amazônia de ampliar a ordenação para além dos estreitos círculos de homens que fizeram o voto de celibato, foi ignorado. Pediram pão e receberam pedras (Mateus 7:1).

A instituição continua a hesitar quanto ao diaconato, formando uma segunda comissão para estudar a questão após a primeira comissão

Marvin M. Ellison e Judith Plaskow, Editors, Heterosexism in Contemporary World Religion: Problem and Prospect, Cleveland: The Pilgrim Press, 2007. Ver especialmente Mary E. Hunt, "Eradicating the Sin of Heterosexism" pp. 155-176. Ver também, Mary E. Hunt, "Just Good Sex" em Good Sex: Feminist Perspectives from the World's Religions, organizado por Patricia Beattie Jung, Mary E. Hunt e Radhika Balakrishnan. New Brunswick, New Jersey: Rutgers University Press, 2001, Ch. 11, pp.158-173. No mesmo volume, o capítulo 6, da especialista em ética e feminista católica, Patricia Beattie Jung, "Sanctifying Women's Pleasure" acrescenta uma importante dimensão à conversa sobre o prazer.

3 Esta coleção inicial redefiniu a questão de mulheres não serem elegíveis para ordenação em termos patriarcais chamando atenção para o fato da "não ordenação" das mulheres pelas autoridades eclesiais, e de como a causa disso e o resultado foi abrir diversas questões relacionadas ao poder. 
que, como seria de se esperar devido à sua constituição diversa, não conseguiu chegar a um consenso (Phyllis ZAGANO, 2020)4. Entretanto, sacerdotisas estão sendo atualmente ordenadas em grupos tais como o Roman Catholic Womenpriests (Sacerdotisas Católicas Romanas), a Association of Roman Catholic Women Priests (Associação das Sacerdotisas Católicas Romanas), a Old Catholic Church (Antiga Igreja Católica) e, em muitas comunidades de base. O Vaticano não reconhece tais ordenações apesar das reivindicações das mulheres pela Sucessão Apostólica. Em alguns casos, o Vaticano ficou tão perturbado a ponto de excomungar as mulheres envolvidas. Mas um rápido levantamento de católicos envolvidas no culto e na vida comunitária com estas mulheres na liderança mostra que eles/as prontamente identificam estas ministras como sacerdotisas católicas. Este gênio está fora da garrafa.

Mulheres com formação católica estão sendo ordenadas em números recordes em muitas denominações protestantes. Por exemplo, nos Estados Unidos, a United Church of Christ (Igreja Unida de Cristo), a Lutheran Church in America (LCA, Igreja Luterana na América), a Episcopal Church (Igreja Episcopal, que é parte da comunhão Anglicana mundial) e a Unitarian Universalist Association (Associação Universalista Unitária) contam com muitas mulheres vindas do catolicismo em seu clero.

Sem negar as escolhas das mulheres em trocar de denominação, algumas relatam que ainda "se sentem" católicas, que foram formadas pelos valores e sensibilidades litúrgicas católicas. É cada vez mais comum se referir a elas como mulheres católicas que foram ordenadas, e também como participantes integrais de uma outra tradição. Se por um lado isso pode parecer uma contradição no pensamento patriarcal, é perfeitamente normal, apenas de maior complexidade do que os pensadores institucionais parecem ser capazes de entender. Não se pode negar a existência de mulheres católicas ordenadas desta forma, porque elas não se conformam ao pensamento anterior, binário e exclusivista.

Há muitas novas expressões de igreja nas quais novos modelos de ministério feminista estão se desenvolvendo. Por exemplo, no movimento Women-Church (mulheres-igreja), pequenas comunidades de base feministas geralmente se valem de uma liderança compartilhada

Dr. Zagano atuou na primeira Comissão para o Estudo do Diaconato de Mulheres. 
ignorando inteiramente assim a questão da ordenação. A teologia da Eucaristia, em tais comunidades, não é dependente de um senso biológico dos mistérios sagrados realizados por um padre intermediário entre a comunidade e o Divino. Antes, baseia-se na sacralidade compartilhada das pessoas reunidas para dar graças e viver seu compromisso de dedicar-se ao trabalho solidário.

Todas estas questões são fruto de décadas de pesquisa e prática que, porém, se articulam para promover um tipo diferente de catolicismo - inclusivo, que acolhe todas e todos à Mesa e é parte de esforços religiosos globais mais amplos que buscam um terreno comum para o bem comum. Está bem longe dos agitados esforços, moralmente desconfortáveis, da igreja institucional de defender seus interesses, de criar uma igreja mais tacanha, mais desencarnada, na qual mesmo quando muitos desejam se identificar como católicos, e menos aqueles que não o querem, não se sentem bem-vindos. As feministas católicas não participarão de tal farsa. Nós temos criado, e continuaremos a criar, alternativas amplas.

\section{CONCLUSÃO}

À luz das mudanças na composição dos fiéis, de novas formas de entender a teologia moral e de uma ampla variedade de opções ministeriais, fica claro que o catolicismo romano numa mais será o mesmo. O que está emergindo não prioriza Roma como centro do universo católico. Ao contrário, muitas culturas e regiões são incentivadas a encontrar seus próprios caminhos, a ter uma prática condizente com as necessidades pastorais de seus membros. Que o Sínodo da Amazônia tenha voltado de mãos vazias, ignorando as necessidades profundas e claramente expressas do povo daquela região, significa que qualquer pessoa que tenha esperança de muitas mudanças na instituição terá que esperar por muito tempo. Num mundo atormentado por uma pandemia, repleto de exploração étnico-racial e econômica, sob séria ameaça de ser destruído tanto pela possibilidade de uma guerra nuclear quanto pelo crescente ecocídio, não há tempo a perder.

Zeca e suas companheiras podem se orgulhar pelas mudanças radicais por meio das quais nós redesenhamos e reformulamos aspectos 
fundamentais da tradição católica. Depois de dois milênios de teologia e liderança masculina tóxica, estamos oferecendo mudanças no atacado, numa miríade de formas. O quanto somos personae non gratae nos círculos eclesiais oficiais é um indício de nosso impacto. Podemos nos encantar com o fato de que muitas pessoas, a maioria mulheres, cada vez mais outros também, encontraram maneiras de reproduzir saúde e justiça, novos modos de ser religiosas com seus próprios termos e novas formas expansivas e multifacetadas de ser comunidade espiritual.

À Zeca, ofereço do fundo do meu coração o meu "Obrigada" e um caloroso brinde "Ad multos anos". Juntas com muitas companheiras, continuamos o trabalho de redesenhar e reformular com vigor, contentes por saber que muitas mulheres (e homens) viveram e viverão vidas mais saudáveis, mais felizes e mais frutíferas por causa de nossos esforços.

\section{REFERÊNCIAS}

DALY, Mary. Beyond God the Father: Toward a Philosophy of Women's Liberation. Boston: Beacon Press, 1973.

ELLISON, Marvin M.; PLASKOW, Judith (Eds.). Heterosexism in Contemporary World Religion: Problem and Prospect. Cleveland: The Pilgrim Press, 2007.

HARRISON, Beverly Wildung. Our Right to Choose: Toward a New Ethic of Abortion. Boston: Beacon Press, 1984.

JOHNSON, Ian. Vatican adopts a softer line in opposing U.N. women's conference declaration. September 16, 1995. Available on: < https://www.baltimoresun.com/news/ bs-xpm-1995-09-16-1995259075-story.html >.

HOLY SEE PRESS OFFICE. Presentation of the Pontifical Yearbook 2019 and the Annuarium Statisticum Ecclesiae 2017, 06.03.2019. Available on: < https://press.vatican.va/ content/salastampa/en/bollettino/pubblico/2019/03/06/190306b.html >.

MASCI, David; SMITH, Gregory A. 7 facts about American Catholics. Pew Research Center, October 10, 2018. Available on: < https://www.pewresearch.org/fact-tank/2018/10/10/7-facts-about-american-catholics/ $>$.

HUNT, Mary. Eradicating the Sin of Heterosexism. In: ELLISON, Marvin M.; PLASKOW, Judith (Eds.). Heterosexism in Contemporary World Religion: Problem and Prospect. Cleveland: The Pilgrim Press, 2007, p. 155-176.

. Just Good Sex. In: JUNG, Patricia Beattie; HUNT, Mary E.; BALAKRISHNAN, Radhika (Eds.). Good Sex: Feminist Perspectives from the World's Religions. New Brunswick: Rutgers University Press, 2001, p.158-173. 
JUNG, Patricia Beattie. Sanctifying Women's Pleasure. In: In: JUNG, Patricia Beattie; HUNT, Mary E.; BALAKRISHNAN, Radhika (Eds.). Good Sex: Feminist Perspectives from the World's Religions. New Brunswick: Rutgers University Press, 2001, ch. 6.

MILLER, Patricia. The Story Behind The Catholic Church's Stunning Reversal On Contraception. June 5, 2014. Miller reports on Rosemary Radford Ruether's early work on birth control. Available on: < https://religiondispatches.org/the-story-behind-the-catholic-churchs-stunning-reversal/\#: :text=In\%201964\%2C\%20another\%2obudding\%20 theologian $\% 20$ named $\% 20$ Rosemary $\% 20$ Radford,into $\% 20$ the $\% 20$ living $\% 2$ orooms $\% 200 f \% 20$ Main\%20Street\%20America >.

RAPOZA, Kenneth. Catholic Shrinkage: has Brasil Given Up on Jesus? Forbes, December 27, 2016. Available on: < https://www.forbes.com/sites/kenrapoza/2016/12/27/brazil-jesus-catholic-datafolha-survey/\#2812ag917609 >.

SCHÜSSLER-FIORENZA, Elisabeth; HÁRING, Hermann (Eds.). Non-Ordination of Women and the Politics of Power, Concilium, 199/3. London: SCM Press, Maryknoll, NY: Orbis Books, 1999.

VATICAN NEWS. Pope appoints woman under-secretary in Vatican Secretariat of State. Jan. 15, 2020. Available on: < https://www.vaticannews.va/en/vatican-city/news/2020-01/ pope-appoints-woman-undersecretary-in-secretariat-of-state.html $>$.

WEXLER, Celia Viggo. Pope Francis put a woman in a top Vatican role. It shows how little power Catholic women hold. January 21, 2020. Available on: < https://www.nbcnews. com/think/opinion/pope-francis-put-woman-top-vatican-role-it-shows-how-ncna1119661 >.

ZAGANO, Phyllis. Women: Icons of Christ. Mahwah: Paulist Press, 2020.

Submetido em: 7-10-2020

Aceito em: 21-10-2020

Mandrágora, v.26, n. 2, 2020, p. 95-111 